\title{
Effect of Microwave Exposure on the Blood Sugar Metabolism in Rat and the Role of Vitamins $\mathrm{C}$ and $\mathrm{E}$
}

\author{
Meindinyo, R.O.K., Aweda, M.A. \\ Department Of Radiation Biology, Radiotherapy and Radiodiagnosis, College Of Medicine Of The University of \\ Lagos/Lagos University Teaching Hospital Idi-Araba, P.M.B 12003 Lagos, Nigeria.
}

\begin{abstract}
:
AIM: To investicate the immediate effects of whole body exposure to $2.450 \mathrm{GHZ}$ Microwave (mw) exposure on the blood sugar metabolism.

Materials And Methods: 120 adult wistar rats were used. The rats were grouped in fives. 6 groups of five served as control at various times. Another 6 groups of five were exposed to MW without administration of antioxidants. 6 groups were treated with vitamin $C, 1 \mathrm{mg} \mathrm{kg} \mathrm{kg}^{-1}$ body weight, while another 6 groups were treated with vitamin E, also $1 \mathrm{mg} \mathrm{kg}^{-1}$ body weight, and 4 days before exposure in both cases.

Results: The results show that the microwave exposure caused the Blood Sugar level (BLS) to vary between the mean values of $98.4 \pm 1.2 \mathrm{~g} / \mathrm{d}$ and $98.0 \pm 4 \mathrm{~g} / \mathrm{dl}$ for the males and females respectively. Immediately after irradiation the value of the BLS rose to $105.4 \pm 1.2 \mathrm{~g} / \mathrm{dl}$ from $68.2 \pm 0.6 \mathrm{~g} / \mathrm{dl}$ for the males and to $106.3 \pm 1.1$ from $66.1 \pm 0.8 \mathrm{~g} / \mathrm{dl}$ for the females. The value further increased to $140.3 \pm 0.8 \mathrm{~g} / \mathrm{dl}$ for the males and $141.1 \pm 0.4$ for the females within the first 24 hours. The values then decreased gradually to $119.1 \pm 1.0 \mathrm{~g} / \mathrm{dl}$ and $118.2 \mathrm{~g} / \mathrm{dl}$ for the males and females respectively after 8 weeks. The effects of the administered antioxidants, vitamins $C$ and $E$ on these parameters were to also studied for the same period. $1 \mathrm{mg} / \mathrm{kg}$ body weight of vitamins $C$ administered continuously for four days before irradiation resulted in a decrease in the BLS from the .normal value to a minimum of $131.2 \pm 0.3 \mathrm{~g} / \mathrm{dI}$ and $124.3 \pm 3.3 \mathrm{~g} / \mathrm{dl}$ forthe males and females respectively. Also $1 \mathrm{rngkg}{ }^{1}$ of vitamin $E$ administration similarly resulted in decrease of the parameters from $129.2 \pm 0.4$ and $128.2 \pm$ $0.29 \mathrm{~g} / \mathrm{dl}$ respectively for the males and females within the first day: The values then gradually increased to the normal towards the end of the $8^{\text {th }}$ weeks.
\end{abstract}

Conclusion: Exposures to $M W$ radition affect the blood sugar that may have negative health impacts. Administration of vitamins $C$ and $E$ may cushion the potential deleterious health hazards.

Keywords: Microwave exposure, blood sugar, vitamins, male rats, female rats

\section{Introduction}

The ever increasing applications of microwaves (MW) in industry, medicine and scientific research have resulted in significant exposure of the human populace to their associated biological effects and hazards. This proliferation of microwaves sources and application has equally evoked tremendous research interests over their suspected adverse effects on biological systems. Some of these studies have shown that, for the broad range of frequencies between $300 \mathrm{kHz}$ and $300 \mathrm{GHz}$, cutaneous perception of heat and thermal pain may be an unreliable sensory mechanism for protection against potentially harmful radio frequency radiation exposure levels. This is because RF energy can be-absorbed in tissue without response of the cutaneous thermal receptors, and this adverse effect occurring at temperatures below the threshold $\left(45^{\circ} \mathrm{C}\right)$ of thermal pain $(1,2)$. Other researchers reported cataract inducement in laboratory animals due to exposure, testicular degeneration as well as internal bleeding among radar equipment workers $(3)$. Other workers $(4,5,6)$ reported the immunostimulatory effect of (MW) radiation as well as the effect of (MW) emitted by cellular phones on the slow brain potentials (SP) and brain cancer. The molecular phenomena involved in the conversion electromagnetic (EM) energy to heat and the biological implications have been extensively reviewed in the literature $(7,8)$. Microwaves interactions occur through the stimulation of e excitable membranes of nerve and muscle cells. Those associated with heating lead to perturbation in biological reactions, reaction rates current flow and e ruction of cell membranes $(9,10,11,12)$, thereby producing some observable and measureable physiological parameters. Some studies have shown that exposure to (MW) radiation produced effects which include activation of peritoneal macrophages to a viricidal state (12), increased immune response (13), modification of the lipid peroxidation conditions $(14,15)$. In some of our previous reports $)(14,15)$, we have suggested that many of these effects are caused by free oxygen, free radicals, peroxides and superoxides. Free radicals promote oxidation of amino acid residue side chains, formation of proteinprotein cross-linkages (e.g. sulfhydry I mediated) and oxidation of the protein backbone resulting in fragmentation and aggregation. Oxidative modification enhance degradation of critical enzymes by the multi-catalytic proteasome complex (16), thereby wreaking havoc throughout the cell. This paper 
presents, as part of a series of our studies on radiation safety and protection of MW at most commonly used frequency. This is to determine the effects of exposures on blood sugar metabolism. The results of this study will be essential in the assesment of the health impacts on environmental, professional, occupational and public exposures to the fast growing MW technologies. The knowledge and the awareness of the eventual health impacts would assist in developing protective devices and strategies of minimizing the hazards. Ascorbic acid, a water-soluble vitamin plays essential metabolic roles in vivo, it is a good scavenger of reactive oxygen species and it also helps to recycle $\alpha$-tocopherol in vivo (17). Vitamin $\mathrm{E}$ is a major membrane bound antioxidant present in the lipid core of cell membranes and lipoproteins where it protects polyunsaturated fats from free radical-mediated peroxidation. It is also essential along with cholesterol, for the structural stability of the membrane (18). Suspecting that changes in the biochemical parameter in this study is due to oxidation processes, the effects of administering these anti-oxidants to MW exposed organisms were studied to determine their eventual modifying role on the studied parameter.

\section{Calibration of Microwave Source}

\section{Material And Methods}

The MW generator model ER660E, Serial No MX704CCR from Toshiba UK Ltd available in the Department of Radiation Biology and Radiotherapy, College of Medicine of the University of Lagos was used for the study. The MW detector was the non-interacting thermistor RS 141, which has a resistance of $4.7 \mathrm{k} \Omega$ at $250 \mathrm{C}$. The thermistor was pre-calibrated in a $12 \mathrm{~cm} * 6 \mathrm{~cm} * 4 \mathrm{~cm}$ size water phantom with the aid od a digital readout and a mercury-in-glass thermometer as reference. Details of the calibration procedures have been described elsewhere $(14,15)$.

\section{Determination of Specific Absorption Rate (SAR)}

Determinaton of the SAR was done by inserting the thermistor probe into the rectum of the animal during exposure following the method of Guy et al (19) with slight modificationto adapt to local requirements. The irradiation chamber surfaces were lagged with water to minimize the reflective properties which may increase the heating rate (3). The generator was operated at room conditions of $252 \pm{ }^{0} \mathrm{C}$ and $56+4 \%$ relative humidity. Exposures were total body with the animal at placed $12 \mathrm{~cm}$ ftrom the MW antenna. The SAR values were obtained using the methods that have been described elsewhere (14).

\section{Animal and Sample Preparations}

120 wistar rats of both sexes, 6-8 weeks old weighing $0.090-0.130 \mathrm{~g}$, obtained from the laboratory Animal centre of the College of Medicine, University of Lagos were used. The care of the rats in conformity with the International, National and Institutional guidelines for care and use of laboratory animals in Biomedical Research according to the Canadian Council of Animal Care (1985). The rats were feed with standard rat chou obtained from Pfizer Nig. Ltd, Lagos, Nigeria, and they had free access to drinking water. The animals were firstly acclimatized to the laboratory conditions of $12 \mathrm{~h} / 12 \mathrm{~h}$ of dark /light cycle. The animals were grouped into 6 , each group comprising of 20 rats. 5 of the 20 in each group served as control (without exposure to MW), while another 5 were exposed to MW radiation. Another group of 5 were administered with vitamins $\mathrm{C}$ before irradiation while the last group of 5 was administered with vitamin $\mathrm{E}$.

\section{Animal irradiation}

The rats were irradiated from the open side of the rectangular horn-antenna, each placed in a plastic cage measuring $5 \times 10 \times 25 \mathrm{~cm}$. The field intensity of the animal location was determined with aid of the thermistor connected to a readoutmeter developed by the research team. The field distribution in these regions was bell-shaped with a central maximum value of $6 \mathrm{mWcm}^{-2}$ and a power density of $10 \mathrm{mWcm}^{-2}, 5 \mathrm{~cm}$ from the centre. The rats were allowed free movement during exposures. The local variation on incident power density was measured in the presence and absence of the animal, this variation did not exceed $3 \%$, thus the total variation of power was between 5.5 and $6.0 \mathrm{mWcm}^{-2}$.

\section{Estimation of Blood Sugar}

The enzymatic colorimeter method described by Trinder, (20) was used in the determination of the blood to glucose concentrations in the different samples, the depropteinized blood plasma was decanted and the supernatant stored in a closed vessel for three days. $0.2 \mathrm{ml}$ of this as then mixed with $0.2 \mathrm{ml}$ of the standard solution of glucose and $2 \mathrm{mls}$ of the reagent mixture consisting of a buffer solution and enzymes. It was then incubated for about 60 minutes at $25^{\circ} \mathrm{C}$ after which the absorbance of the sample and of the standard were determined using a wavelength of $546 \mathrm{~nm}$ and a cuvette of $1 \mathrm{~cm}$ light path. Hence, concentration of $\mathrm{g} / \mathrm{dl}$ is given by 


\section{$\frac{\text { Absorbance of sample }}{\text { Absorbance of standard }} \times 100$}

The students $\mathrm{t}$ - test was used for the statistical analysis and comparison between the group, with the level of stastitical significance at $\mathrm{P}<0.005$.

\section{Results}

The results obtained from this study are presented in table $1 \mathrm{a}$ and $1 \mathrm{~b}(\mathrm{M} \pm \mathrm{SD})$ as well as fig. 1a and $\mathrm{lb}$. The values of blood sugar levels (BSL) for the male and female rats measured over a period of 8 weeks after MW exposures, compared with that of unexposed rates are as shown in the fig 1a and 1b. The variation in the control over the monitoring period was small; this was between the mean values of $98.4 \pm$ $1.2 \mathrm{~g} / \mathrm{dl}$ and $98.0 \pm 1.4 \mathrm{~g} / \mathrm{dl}$ for the males and females respectively. Immediately after irradiation the value of the BSL rose to $105 . \pm 1.2 \mathrm{~g} / \mathrm{dl}$ from $68.2 \pm 0.6 \mathrm{~g} / \mathrm{dl}$ for the males and from $106.3 \pm 1.1$ to $66.1 \pm 0.8 \mathrm{~g} / \mathrm{dl}$ for the females. The values further increased to $140.3 \pm 0.8 \mathrm{~g} / \mathrm{dl}$ for the males and females and $141.1 \pm 0.4$ for the females within the first 24 hours and then decreased gradually to $119.1 \pm 1.0 \mathrm{~g} / \mathrm{dl}$ and $118.2 \pm 0.2 \mathrm{~g} / \mathrm{dl}$ for the males and females respectively after 8 weeks. The effects of the administered anti-oxidants, vitamins $\mathrm{C}$ and $\mathrm{E}$ on these parameters were also studied for the same period. $1 \mathrm{mg} / \mathrm{kgl}$ body weight of vitamins $\mathrm{C}$ administered continuously for four days before irradiation resulted in a smaller rise in the BSL from the normal values to a minimum of $131.2 \pm 0.3 \mathrm{~g} / \mathrm{dl}$ and $132.0 \pm 0.4 \mathrm{~g} / \mathrm{dl}$ for the males and females respectively one day after exposure. Also $1 \mathrm{mg} / \mathrm{kg}$ of vitamin $\mathrm{E}$ administration similarly resulted in decrease of the parameters from $124.5 \pm 1.2$ and $126.5 \pm 3.1 \mathrm{~g} / \mathrm{dl}$ within the first day. The values then gradually increased to the normal toward the end of the $8^{\text {th }}$ week.

Table 1. Variation Of Blood Sugar (Blg) Levels Over A Period Of 8 Weeks After Mw Exposure And Administration Of Vitamin C And E. (For Male Rats).

\begin{tabular}{|l|l|l|l|l|}
\hline TIME & IRR & IRR + VITC & IRR + VITE & CONTROL \\
\hline IMM & $105.0 \pm 0.6$ & $110.3 \pm 4.4$ & $122.5 \pm 1.4$ & $98.4 \pm 1.4$ \\
\hline 1 DAY & $140.3 \pm 0.8$ & $131.0 \pm 0.4$ & $124.5 \pm 3.2$ & $100.1 \pm 1.0$ \\
\hline 1 WEEK & $132.0 \pm 6.4$ & $58.0 \pm 0.6$ & $119.5 \pm 0.6$ & $97.9 \pm 2.6$ \\
\hline 2 WEEKS & $78.5 \pm 0.5$ & $68.7 \pm 0.7$ & $73.3 \pm 1.7$ & $99.1 \pm 2.1$ \\
\hline 4 WEEKS & $124.0 \pm 1.0$ & $137.0 \pm 0.9$ & $73.3 \pm 1.4$ & $98.6 \pm 1.2$ \\
\hline 8 WEEKS & $119.1 \pm 1.0$ & $112.3 \pm 0.8$ & $93.0 \pm 1.0$ & $96.1 \pm 1.2$ \\
\hline
\end{tabular}

Table 2. Variation Of Blood Sugar (Blg) Levels Over A Period Of 8 Weeks After Mw Exposure And Administration Of Vitamin C And E. (For Female Rats).

\begin{tabular}{|l|l|l|l|l|}
\hline TIME & IRR & IRR + VITC & IRR + VITE & CONTROL \\
\hline IMM & $105.0 \pm 0.6$ & $110.3 \pm 4.4$ & $122.5 \pm 1.4$ & $98.4 \pm 1.4$ \\
\hline 1 DAY & $141.3 \pm 0.8$ & $132.0 \pm 0.4$ & $126.5 \pm 3.4$ & $100.8 \pm 1.2$ \\
\hline 1 WEEK & $132.0 \pm 6.0$ & $57.0 \pm 1.6$ & $119.0 \pm 0.4$ & $98.5 \pm 2.0$ \\
\hline 2 WEEKS & $77.0 \pm 0.6$ & $66.8 \pm 0.7$ & $73.8 \pm 1.4$ & $99.5 \pm 2.4$ \\
\hline 4 WEEKS & $122.0 \pm 1.8$ & $136.0 \pm 1.9$ & $73.5 \pm 1.4$ & $97.5 \pm 1.2$ \\
\hline 8 WEEKS & $118.8 \pm 1.0$ & $113.8 \pm 0.8$ & $95.0 \pm 1.0$ & $96.8 \pm 1.4$ \\
\hline
\end{tabular}

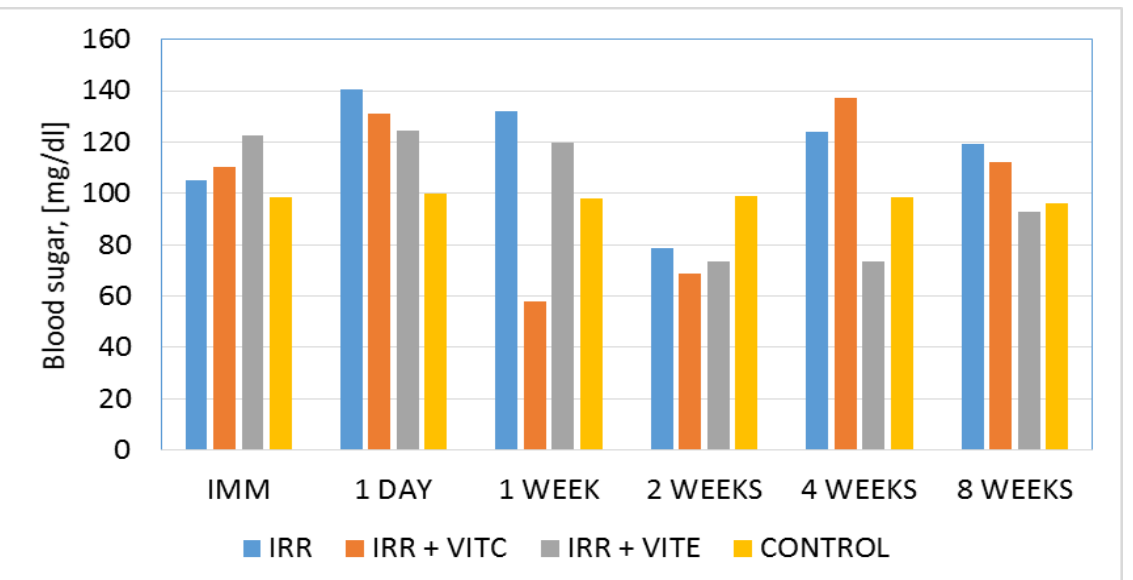

Figure 1a. Comparison of blood sugar level before and after Micro Wave exposure, and administration of vitamin $\mathrm{C}$ and $\mathrm{E}$ (male rats). 


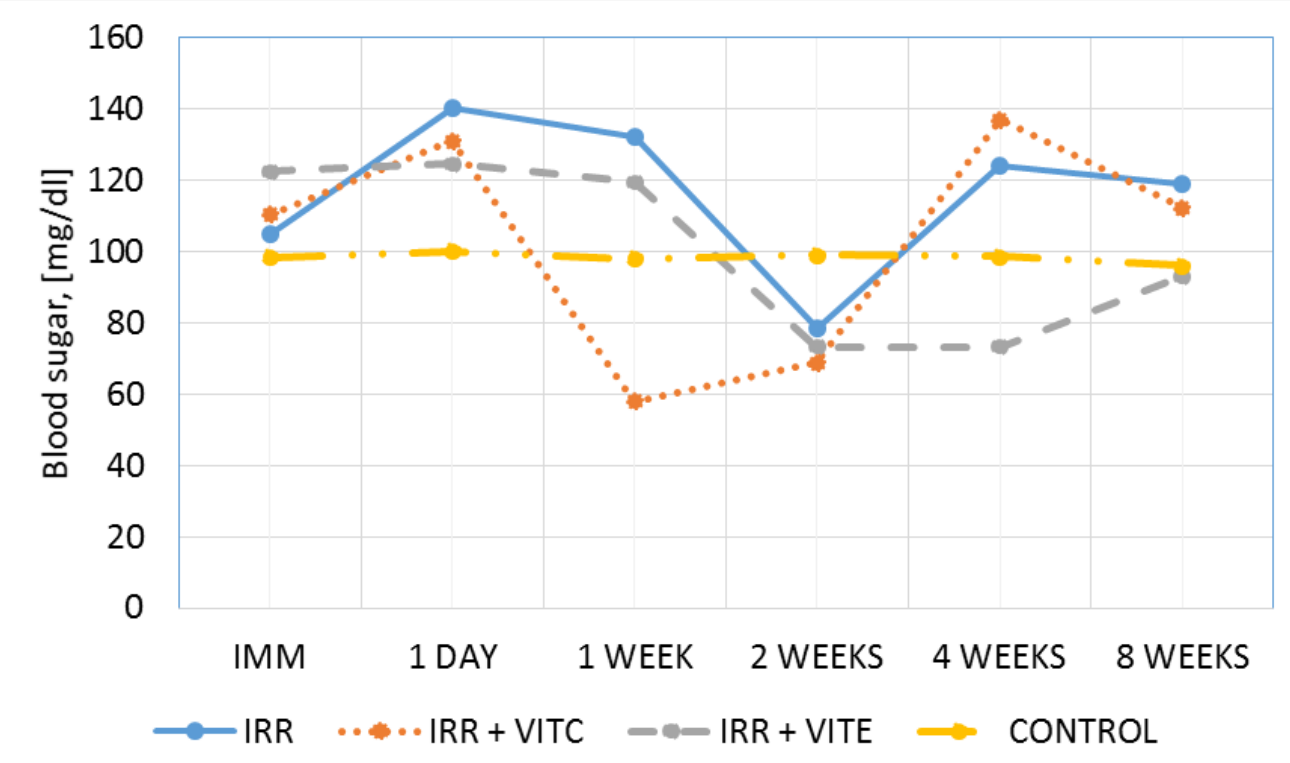

Figure 2b. Comparison of blood sugar level before and after Micro Wave exposure, and administration of vitamin $\mathrm{C}$ and $\mathrm{E}$ (male rats).

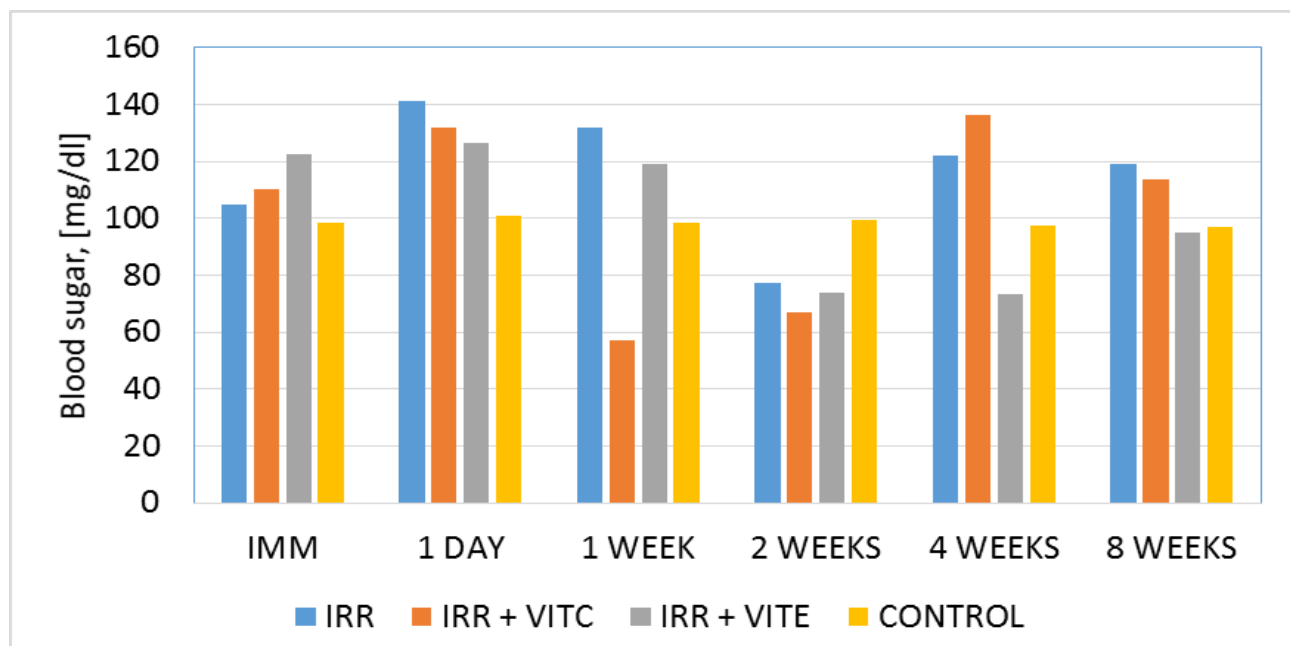

Figure 2a. Comparison of blood sugar level before and after Micro Wave exposure, and administration of vitamin $\mathrm{C}$ and $\mathrm{E}$ (female rats).

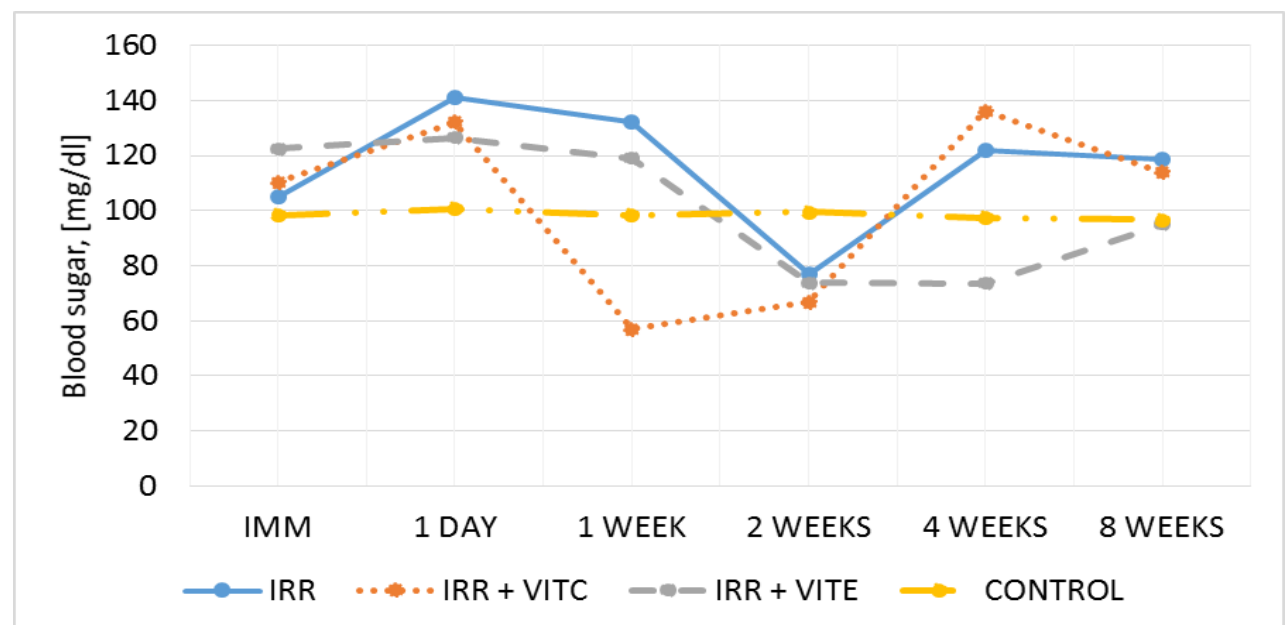

Figure 2b. Comparison of blood sugar level before and after Micro Wave exposure, and administration of vitamin $\mathrm{C}$ and $\mathrm{E}$ (female rats). 


\section{Discussion}

As can be seen from figures $1 \mathrm{a}$ and $2 \mathrm{~b}$, the MW exposure of the rats does affect the level of the blood sugar quite significantly $(\mathrm{P}<0.005)$. Also the vitamins $\mathrm{C}$ and $\mathrm{E}$ supplementation led to modification of the effects on the parameter. This is consistent with the report by Paolisso(21) that pharmacological dose of antioxidants vitamin $\mathrm{E}$ increased insulin stimulated glucose uptake. Also, Clackson et al., (22) showed that vitamin(s) $\mathrm{C}$ and $\mathrm{E}$ supplementation may provide a protective effect on oxidative stress as may be induced by exercise. The observed rise in the BSL level in the irradiated groups is suspected to be enzyme and or hormonal inactivation especially insulin due to the excess free radicals produced during MW exposure of the irradiated rats. The excess free radicals so produced may lead to lipid peroxidation due to oxidative damage to LDL on cellular membrane. It has been reported that vitamins $\mathrm{C}$ and $\mathrm{E}$ may improve insulin responsiveness in normal and reported diabetic patients, perhaps because of their role as antioxidants (23). Increased free radical formation and lipid peroxidation have been observed in diabetes. $(24,25)$. Increased lipid peroxidation may cause changes in membrane permeability affecting membrane fluidity, potentially affecting the binding of insulin $t$ its receptor, affecting the activities of glucose transporters and decreases in glucose uptake (23). It has also been hypothesized that pancreastic islet cells might be sensitive to free radical injury when they have low antioxidant enzyme activity Antioxidant defense helps to scavenge the free radicals involved in all these damage especially vitamin E (23). It is suspected in this study that the inhibition of blood sugar metabolism may have resulted in the stimulation of the metabolism of alternative energy release processes like metabolism of triglycerides. This may probably explain the observation made in a previous work by the authors (24) who reported that the microwave exposure lead to increased metabolism of triglycerides in the exposed rats. It may therefore be suggested that the exposure of the rats to the $2.45 \mathrm{GHz}$ microwaves resulted on the inhibition of the activities of certain enzymes involved in the metabolism of blood sugar like insulin.

\section{Conclusion}

The results of this study demonstrate the exposure to MW radiation may affect the blood sugar. This may have negative health consequences especially among those that are pro fessionally and occupationally expose on regular basis. The fast growing MW technologies and diversification of industrial, domestic and medical applications make it indispensible for the generality of the unsuspecting public to know and be conscious of the potential health detriments of MW exposures. The results of the administration of vitamins $\mathrm{C}$ and $\mathrm{F}$, which cushion the undesirable effects suggests that, in addition to regular haematological examinations, diets fortified with effective antioxidants may be recommended for those who may not but be exposed to MW radiation during routine practice of their profeesion, discharge of occupation duties or orther uses of MW generating devices.s

\section{Acknowledgments}

The authors are grateful to Dr. S. Gbenebitse and Prof. O. Adegbenro of the College of Medicine of University of Lagos, and University Teaching Hospital Idi-Araba for providing tecnical support for this work.

\section{Conflict of interest}

The authors declare no conflict of interests.

\section{Reference}

[1]. Stuckly,M.A(1979) Interaction of Radiofrequency and MW Radiations with living Systems. A review of Mechanisms. Rad. Environ. Biophysics. 16: 1-14.

[2]. Adair, E.R. (2002) Biological Effects of Radio-Frequency/Microwave Radiation, IEEE Transaction on Microwave Theory and techniques 50(1):953-958.

[3]. Bren. SP.A (1996) Historical Introduction to Electromagnetic Field Health effects IEEE. Engineering in Medicine and Biology

[4]. Novoselova E. G.Fenseko E. E, Maker V. P.,. and SaDovnikov V. B.(1999): Microwaves and cellular immunity I: Effects of Whole body Microwave Irradiation on Tumor Necrosis Factor Production in Mouse Cwells" Bioelectrochemistry and Bioenergetics, vol 49, pg $29-35$.

[5]. Fenseko E. E., Maker V. P., Novoselova E. G. and SaDovnikov V. B.(2002): Microwaves from cellular phones affect the slow brain potentials Bioelectrochemistry and Bioenergetics, vol 52, pg 20 - 25.

[6]. Zada G. (2014) Mobile, cordless phones and brain cancer. Science Guadian column of the guardian NP $15^{\text {th }}$ July, 2014.

[7]. Schwan H.P and Foster K.R(1980) RF-field Interaction with Biological System Proceedings of the Institute of Electrical Engineering. 68: 104-113.

[8]. Mc Ree D.T and Davies H.G (1987). Whole body and local dosimetry in rats exposed to 2.45GHz MW Radiation Health Physics 46:315-318.

[9]. Foster K.R (1996) Effect of surface cooling and blood flow on the microwave heating tissues. IEEE, Engineering in medicine and Biology 26(6): 50-54.

[10]. Pichard W.F and Rusanbaum F.J(1978). Biological Effects of MW radiations at Membrane levels: Two possible Athermal Electrophysiological Mechanisms and a Proposed Experimental Tests. Mathematical Biosciences: 39:235-253. 
[11]. Barsoun Y.H. and Pickard WF(1982); Effect of EM Radiation in the Range 40-440 MHz on Vascular Pot of Characeen cells". Bioelectromagnetics, vol. 3 pg.193-201.

[12]. Barsoun Y.H. and Pickard WF(1982); "The Vascular potential of Characean Cells Subjected to EM Radiation in the Range 200$8200 \mathrm{MHz}$. Bioelectromagnetics, vol. 3 pg. $\cdot 393-400$.

[13]. Rao R.G. V, Cain C. A, Lockwood V, and Thomspkins W.A. F(1983) Effect of microwave exposure on Hamsters immune system II: Pentoneal microphage Function. Bioelectromagnetics: 3:393-400.

[14]. Aweda M Gbenebitse S. Meindinyo R O.K. (2003): Effect of $2.45 \mathrm{GHz}$ microwave exposure on the peroxidation status of wistar rats. (Nigerian Postgraduate Medical Journal). Vol. 9 (2) pp $21-24$.

[15]. Aweda M Gbenebitse S. Meindinyo R O.K. (2003): Microwave Radiation affects Hematological Parameters and Antioxidants modify the effects in Rats. on the peroxidation status of wistar rats. International Journal of current Research: 3:140-145.

[16]. Azinge EC, Mabayoje M. Sofola OA (2001) LDL peroxidation and total antioxidant status in Nigerian patient with sickle-cell disease. Nig. J Hosp. Med. 11 (1-4): 46-50.

[17]. Sauberlick H.E (1990). In: Present knowledge in nutrition. Brown ML, (ed) Washington, DC. International Life Sciences Institute.pp 19-20.

[18]. Chiu D(1982). Peroxidation Vitamin E and SCE. Ann NY Acad Sci.:393:323-325.

[19]. Guy A. W(1987) Doosimetry of Exposure to VLF to Microwaves. Health physics: 56:1-6.

[20]. Trinder .P. (1969) Am. Clin. Biochem: 6:21.

[21]. Paolisso G.D, Amore A, Babli B.A (1994), Plasma Vitamin C affects Glucose homeostastis in healthy subjects and in Insulin dependent diabetics Am. J. Physiology 266: E261-8.

[22]. Clackson P. M and Evans W.J (2000) Vitamins and trace minerals in lamb, D.R and Williams M.H (eds) Evogogenics enhancement of performance in exercise and sport. Carmel Cooper Publishing Group. 23 -176.

[23]. Caballero B. (1993) Vitamins which improve the action of insulin. Nutri. Rev. 51: 339-40.

[24]. Aweda M Gbenebitse S. Meindinyo R O.K. (2003): Microwave Radiation affects the HDL, LDL, TCL and TRG of rats. International Journal of Physical Sciences. Vol:17:15-21 